Check for updates

Cite this: RSC Adv., 2018, 8, 4039

Received 25th October 2017

Accepted 16th January 2018

DOI: $10.1039 / c 7 r a 11754 j$

rsc.li/rsc-advances

\section{Structural diversity of six metal-organic frameworks from a rigid bisimidazole ligand and their adsorption of organic dyes $\dagger$}

\author{
Siyu Liu, ${ }^{a}$ Mingming Guo, ${ }^{a}$ Huadong Guo, (D) *a Yingying Sun, ${ }^{a}$ Xianmin Guo, ${ }^{\text {*a }}$ \\ Shaowen Sun ${ }^{a}$ and Eugeny V. Alexandrov (iD)*b
}

Six metal-organic frameworks, namely, $\left[\mathrm{Cd}_{2}(\mathrm{odc})_{2}(2,6-\text { bin })_{2}\right] \cdot\left(\mathrm{CH}_{3}\right)_{2} \mathrm{NH}(1),\left[\mathrm{Cd}_{2}(\mathrm{tdc})_{2}(2,6-\text { bin })_{2}\left(\mathrm{H}_{2} \mathrm{O}\right)_{2}\right](2)$, $\left[\mathrm{Cd}_{2}(\text { bzdc })_{2}(2,6-\text { bin })_{2}\right] \cdot 4 \mathrm{DMF}$ (3), $\left[\mathrm{Cd}_{2}(\mathrm{hfdc})_{2}(2,6-\text { bin })_{2}\right] \cdot \mathrm{H}_{2} \mathrm{O}(4),\left[\mathrm{Cd}_{3}(\mathrm{tpo})_{2}(2,6-\text { bin })_{3}\left(\mathrm{H}_{2} \mathrm{O}\right)_{4}\right] \cdot 2 \mathrm{DMF} \cdot 2 \mathrm{H}_{2} \mathrm{O}$ (5) and $\left[Z n_{3}(b t b)_{2}(2,6\right.$-bin) $] \cdot 8 D M F \quad(6) \quad\left\{2,6\right.$-bin $=2,6$-bisimidazoylnaphthalene, $\mathrm{H}_{2}$ Odc $=4,4^{\prime}$ oxybisbenzoic acid, $\mathrm{H}_{2} \mathrm{tdc}=$ thiophene-2,5-dicarboxyl acid, $\mathrm{H}_{2}$ bzdc = benzophenone-4,4'-dicarboxylic acid, $\mathrm{H}_{2}$ hfdc $=2,2^{\prime}$-bis(4-carboxyphenyl)hexafluoropropane, $\mathrm{H}_{3}$ tpo $=$ tris-(4-carboxylphenyl)phosphine oxide and $\mathrm{H}_{3}$ btb $=4,4^{\prime}, 4^{\prime \prime}$-benzene-1,3,5-triyl-tribenzoic acid\} have been synthesized and structurally characterized. Compound 1 exhibits a three-fold interpenetration of 4T25 network. Compound 2 presents a five-fold interpenetration of dia network. Compound 3 displays a 2D $\rightarrow 2 D$ three-fold interpenetration of sql layers. Compound 4 features a 2D $\rightarrow$ 3D parallel polycatenation of sql layers. Compound 5 exhibits an unusual 3,4,6-connected self-catenated network of 3,4,6T206 topology. Compound 6 shows a rare 3,8-connected self-catenated network of 3,8T72 topology. Their adsorption behaviors to organic dyes have been studied.

\section{Introduction}

Organic dyes have been widely used in medicines and the textile, paper, and printing industries, and the polluted water from dyes poses a significant threat to the environment and human health. ${ }^{1}$ Among various techniques for the removal of water pollutants, adsorption is the most attractive method owing to its simplicity and efficiency. ${ }^{2}$ Consequently, numerous adsorption materials have been extensively investigated, including carbon nanotubes, clay, zeolites, sol-gel adsorbents and polymer resins. ${ }^{3}$ However, these adsorbents often face problems like low adsorption capacity, slow adsorption kinetics, complex preparation process, and chemical or thermal instability. The development of an effective adsorbent that possesses good adsorption ability and selectivity toward dye removal is still a challenge.

Recently, metal-organic frameworks (MOFs) constructed using multifunctional organic ligands as linkers and metal/metal clusters as nodes, have received considerable attention. Owing to their versatile structures, controllable pore size, high surface area and

${ }^{a}$ Department of Chemistry, Changchun Normal University, Changchun, 130032, $P . R$. China. E-mail: hdxmguo@163.com; xian_min@hotmail.com; Fax: +86-43186168210; Tel: +86-431-86168210

${ }^{b}$ Samara Center for Theoretical Materials Science (SCTMS), Samara National Research University, Ac. Pavlov St 1, Samara, Russia 443011. E-mail: aleksandrov_ev1@mail. ru; Fax: +7-846-3356798; Tel: +7-846-3356798

$\dagger$ Electronic supplementary information (ESI) available: XRD, TGA. CCDC 1576790-1576795. For ESI and crystallographic data in CIF or other electronic format see DOI: $10.1039 / \mathrm{c} 7 \mathrm{ra11754j}$ thermal stability, MOFs have been extensively investigated as a new class of solid adsorbents. ${ }^{4}$ In view of the big size of dye molecules, only MOFs with large pore size can adsorb dye molecules into the pores; ${ }^{5}$ while for others, dyes are mostly adsorbed

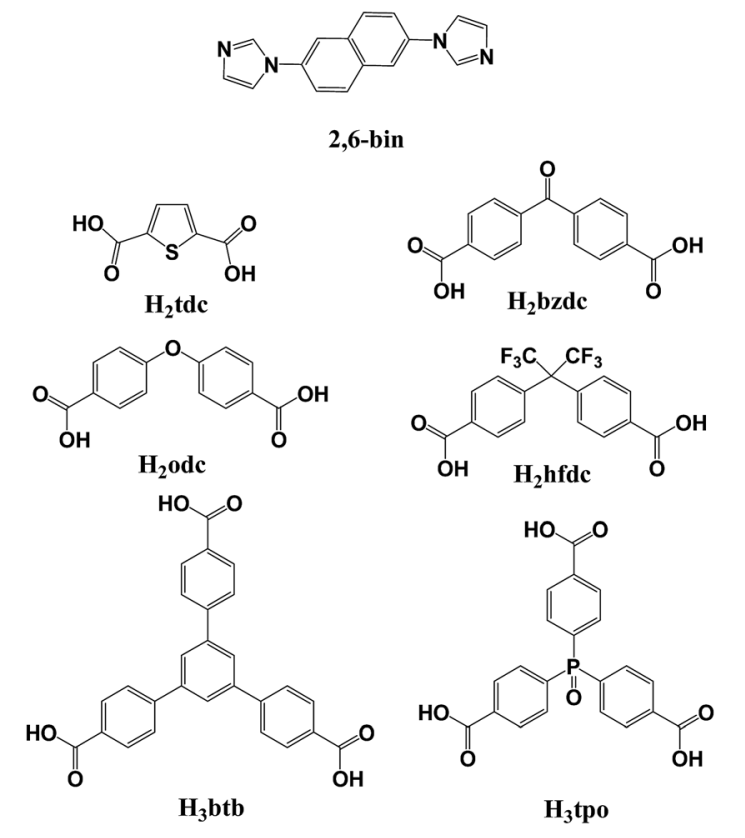

Scheme 1 The building units that were used. 
on the external surface of materials. Thus, the surface physicochemical interactions between the dye molecules and MOF external surfaces, including hydrogen bonding, electrostatic interactions, $\pi-\pi$ interaction, play a vital role in the adsorption of dyes. ${ }^{6}$ In this work, we chosed 2,6-bis(imidazole-1-yl)naphthalene (2,6-bin) as the building unit to construct new MOFs, because its rigid aromatic cycle can definitely promote the $\pi-\pi$ interaction with dye molecules. Meanwhile, by the mixed-ligand strategy, a series of polycarboxylic acids with different conformations were introduced (Scheme 1), in order to evaluate the variable coordination environment and electroaffinity of metal ions to the adsorption of dyes. Successfully, we have synthesized six new MOFs, namely $\left[\mathrm{Cd}_{2}(\mathrm{odc})_{2}(2,6-\mathrm{bin})_{2}\right] \cdot\left(\mathrm{CH}_{3}\right)_{2} \mathrm{NH}(\mathbf{1}),\left[\mathrm{Cd}_{2}(\mathrm{tdc})_{2}(2,6-\right.$ bin $\left.)_{2}\left(\mathrm{H}_{2} \mathrm{O}\right)_{2}\right](2),\left[\mathrm{Cd}_{2}(\text { bzdc })_{2}(2,6-\text { bin })_{2}\right] \cdot 4 \mathrm{DMF}(3),\left[\mathrm{Cd}_{2}(\mathrm{hfdc})_{2}(2,6-\right.$ bin $\left.)_{2}\right] \cdot \mathrm{H}_{2} \mathrm{O}(4),\left[\mathrm{Cd}_{3}(\mathrm{tpo})_{2}(2,6-\mathrm{bin})_{3}\left(\mathrm{H}_{2} \mathrm{O}\right)_{4}\right] \cdot 2 \mathrm{DMF} \cdot 2 \mathrm{H}_{2} \mathrm{O}(5)$ and $\left[\mathrm{Zn}_{3}(\mathrm{btb})_{2}(2,6-\mathrm{bin})\right] \cdot 8 \mathrm{DMF}$ (6). These compounds have been characterized by elemental analysis, thermogravimetric analysis (TGA) and X-ray crystallography. Meanwhile, their adsorption behaviors to organic dyes have been studied.

\section{Experimental section}

All the starting materials were of analytic grade and used as received without further purification. Elemental analyses $(\mathrm{C}, \mathrm{H}$, $\mathrm{N})$ were performed with a Perkin-Elmer 240c elemental analyzer. TGA was performed on a Perkin-Elmer TG-7 analyzer heated from 30 to $800{ }^{\circ} \mathrm{C}$ under nitrogen. Powder X-ray diffraction (PXRD) data were recorded on a Bruker D2 Phaser. UV-vis adsorption spectra were collected on a Shimadzu UV3101PC spectrophotometer to monitor the adsorption progress.

\section{Synthesis of 2,6-bin}

A mixture of $\mathrm{Cu}_{2} \mathrm{O}(0.07 \mathrm{~g}, 0.5 \mathrm{mmol}), 2,6$-dibromonaphthalene (2.86 g, $10 \mathrm{mmol})$, imidazole $(2.72 \mathrm{~g}, 40 \mathrm{mmol})$, and $\mathrm{K}_{2} \mathrm{CO}_{3}$ $(5.52 \mathrm{~g}, 40 \mathrm{mmol})$ in anhydrous DMF $(30 \mathrm{~mL})$ in a $100 \mathrm{~mL}$ twonecked round-bottom flask under $\mathrm{N}_{2}$ was stirred at $150{ }^{\circ} \mathrm{C}$ for $48 \mathrm{~h}$. The reaction mixture was filtered, and then the filtrate was added into $300 \mathrm{~mL}$ of $\mathrm{H}_{2} \mathrm{O}$. The deposit was filtered and washed with water and dried in vacuum to afford the product in $54 \%$. Anal. calcd for $\mathrm{C}_{16} \mathrm{H}_{12} \mathrm{~N}_{4}(\%)$ : C, 73.83; H, 4.65; N, 21.52. Found: C, 73.75; H, 4.60; N, 21.65.

\section{Synthesis of $\left[\mathrm{Cd}_{2}(\mathrm{odc})_{2}(2,6-\mathrm{bin})_{2}\right] \cdot\left(\mathrm{CH}_{3}\right)_{2} \mathrm{NH}(1)$}

A mixture of $\mathrm{Cd}\left(\mathrm{NO}_{3}\right)_{2} \cdot 4 \mathrm{H}_{2} \mathrm{O}(0.0308 \mathrm{~g}, 0.1 \mathrm{mmol}), \mathrm{H}_{2}$ odc (0.0258 g, $0.1 \mathrm{mmol}), 2,6$-bin (0.0260 g, $0.1 \mathrm{mmol}), \mathrm{DMF}(8 \mathrm{ml})$ and $\mathrm{H}_{2} \mathrm{O}(2 \mathrm{ml})$ was placed in a Teflon reactor $(20 \mathrm{ml})$ and heated at $80{ }^{\circ} \mathrm{C}$ for 2 days. After gradually cooled to room temperature at a rate of $10{ }^{\circ} \mathrm{C} \mathrm{h}^{-1}$, colorless crystals of 1 were obtained with $60 \%$ yield based on 2,6-bin. Anal. calcd for $\mathrm{C}_{62} \mathrm{H}_{47} \mathrm{~N}_{9} \mathrm{O}_{10} \mathrm{Cd}_{2}$ : C, 57.16; H, 3.64; N, 9.68. Found: C, 57.30; H, $3.69 ; \mathrm{N}, 9.50$.

\section{Synthesis of $\left[\mathrm{Cd}_{2}(\mathrm{tdc})_{2}(2,6-\mathrm{bin})_{2}\left(\mathrm{H}_{2} \mathrm{O}\right)_{2}\right](2)$}

Complex 2 was synthesized following the same synthetic procedure as that for complex 1 except that $\mathrm{H}_{2}$ tdc was used instead of $\mathrm{H}_{2}$ odc. Colorless crystals of 2 were obtained with $54 \%$ yield based on 2,6-bin. Anal. calcd for $\mathrm{C}_{44} \mathrm{H}_{32} \mathrm{~N}_{8} \mathrm{O}_{10} \mathrm{~S}_{2} \mathrm{Cd}_{2}$ : C, 47.11; H, 2.88; N, 9.99. Found: C, 47.24; H, 2.74; N, 9.83.

\section{Synthesis of $\left[\mathrm{Cd}_{2}(\mathrm{bzdc})_{2}(2,6-\mathrm{bin})_{2}\right] \cdot 4 \mathrm{DMF}(3)$}

Complex 3 was synthesized following the same synthetic procedure as that for complex 1 except that $\mathrm{H}_{2}$ bzdc was used instead of $\mathrm{H}_{2}$ odc. Colorless crystals of 3 were obtained with $56 \%$ yield based on 2,6-bin. Anal. calcd for $\mathrm{C}_{74} \mathrm{H}_{68} \mathrm{Cd}_{2} \mathrm{~N}_{12} \mathrm{O}_{14}$ : C, 56.46; H, 4.35; N, 10.68. Found: C, 56.60; H, 4.39; N, 10.54 .

\section{Synthesis of $\left[\mathrm{Cd}_{2}(\mathrm{hfdc})_{2}(2,6-\mathrm{bin})_{2}\right] \cdot \mathrm{H}_{2} \mathrm{O}(4)$}

Complex 4 was synthesized following the same synthetic procedure as that for complex 1 except that $\mathrm{H}_{2}$ hfdc was used instead of $\mathrm{H}_{2}$ odc. Colorless crystals of 4 were obtained with $52 \%$ yield based on 2,6-bin. Anal. calcd for $\mathrm{C}_{66} \mathrm{H}_{42} \mathrm{~F}_{12} \mathrm{~N}_{8} \mathrm{O}_{9} \mathrm{Cd}_{2}$ : C, 51.35; H, 2.74; N, 7.26. Found: C, 51.46; H, 2.65; N, 7.40.

\section{Synthesis of $\left[\mathrm{Cd}_{3}(\mathrm{tpo})_{2}(2,6-\mathrm{bin})_{3}\left(\mathrm{H}_{2} \mathrm{O}\right)_{4}\right] \cdot 2 \mathrm{DMF} \cdot 2 \mathrm{H}_{2} \mathrm{O}(5)$}

Complex $\mathbf{5}$ was synthesized following the same synthetic procedure as that for complex 1 except that $\mathrm{H}_{3}$ tpo was used instead of $\mathrm{H}_{2}$ odc. Colorless crystals of 5 were obtained with $48 \%$ yield based on 2,6-bin. Anal. calcd for $\mathrm{C}_{96} \mathrm{H}_{86} \mathrm{Cd}_{3} \mathrm{~N}_{14} \mathrm{O}_{22} \mathrm{P}_{2}$ : C, 52.72; H, 3.96; N, 8.97. Found: C, 52.86; H, 3.79; N, 9.11.

\section{Synthesis of $\left[\mathrm{Zn}_{3}(\mathrm{btb})_{2}(2,6-\mathrm{bin})\right] \cdot 8 \mathrm{DMF}(6)$}

Complex 6 was synthesized following the same synthetic procedure as that for complex 1 except that $\mathrm{H}_{3}$ btb was used instead of $\mathrm{H}_{2}$ odc and $\mathrm{Zn}\left(\mathrm{NO}_{3}\right)_{2} \cdot 6 \mathrm{H}_{2} \mathrm{O}$ was used instead of $\mathrm{Cd}\left(\mathrm{NO}_{3}\right)_{2} \cdot 4 \mathrm{H}_{2} \mathrm{O}$. Colorless crystals of 6 were obtained with $49 \%$ yield based on 2,6-bin. Anal. calcd for $\mathrm{C}_{94} \mathrm{H}_{98} \mathrm{~N}_{12} \mathrm{O}_{20} \mathrm{Zn}_{3}: \mathrm{C}$, 59.05; H, 5.17; N, 8.79. Found: C, 59.15; H, 5.25; N, 8.68.

\section{X-ray crystallography}

Single-crystal XRD data for compounds 1-6 were recorded on a Bruker Apex II diffractometer with graphite monochromatized Mo $\mathrm{K} \alpha$ radiation $(\lambda=0.71073 \AA)$ at $285(2) \mathrm{K}$. Absorption corrections were applied using the multiscan technique. All the structures were solved by Direct Method of SHELXS-97 (ref. 7) and refined by the full-matrix least-squares techniques by using the SHELXL-97 (ref. 8) program within WINGX. No-hydrogen atoms were refined with anisotropic temperature parameters. The hydrogen atoms of the organic ligands were refined as rigid groups. For the high vibration, the disordered Ow1 in compound 4 was refined with a total occupancy of 1 and handled by isotropic refinement. The hydrogen atoms of water molecules in compounds 2, 4, 5 are not added. It should be noted that the guest molecules in $\mathbf{6}$ are highly disordered and could not be modeled properly so the diffused electron densities resulting from them were removed by the SQUEEZE routine in PLATON. ${ }^{9}$ The detailed crystallographic data and structure refinement parameters for 1-6 are summarized in Table 1. 
Table 1 Crystal and structure refinement data for compounds 1-6

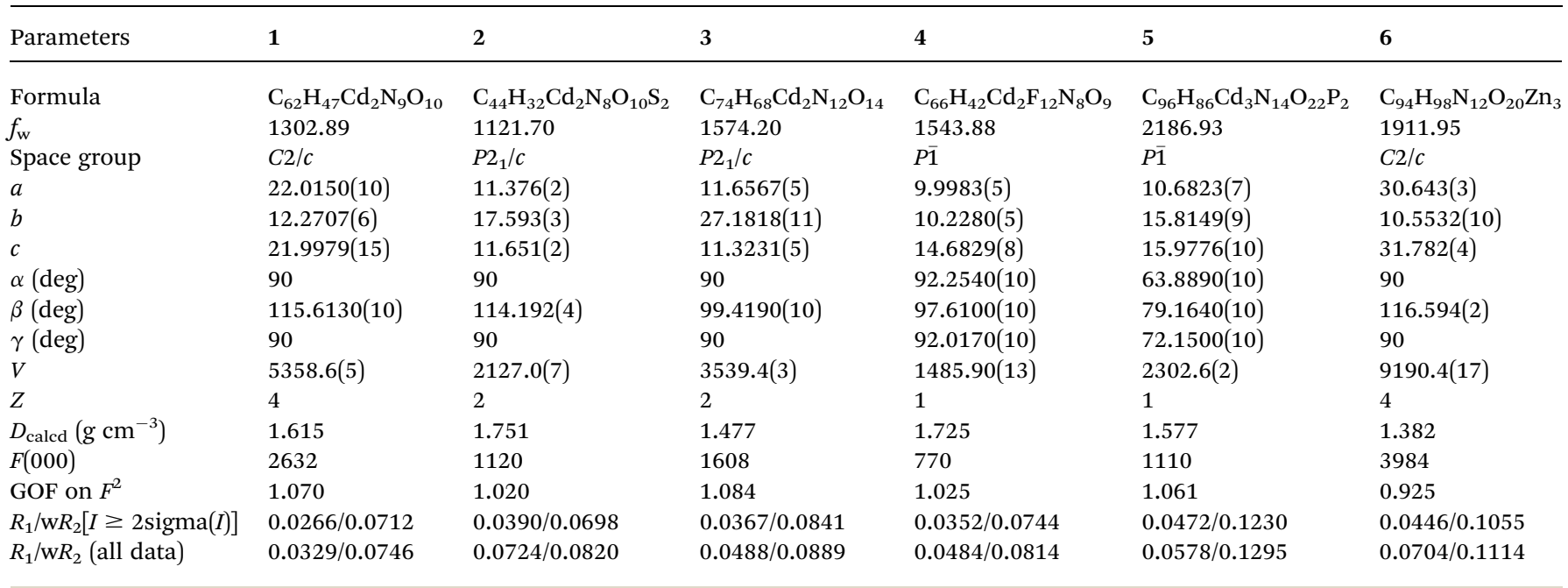

\section{Results and discussion}

\section{Structure description of 1}

Compound 1 crystallizes in a monoclinic space group $P 2_{1} / n$. In the asymmetric unit, there exists one crystallographically unique
Cd(II) atom, one odc ${ }^{2-}$ anion, two half 2,6-bin ligands and one free $\left(\mathrm{CH}_{3}\right)_{2} \mathrm{NH}$. As shown in Fig. 1a, the $\mathrm{Cd}(\mathrm{II})$ atom is ligated by four oxygen atoms from two odc ${ }^{2-}$ anions (Cd-O, 2.2854(16)$2.5380(16) \AA$ ) and two nitrogen atoms from two 2,6-bin ligands (Cd-N, 2.2370(17)-2.2594(18) $\mathrm{A})$. The $\mathrm{Cd}(\mathrm{II})$ to O/N distances and
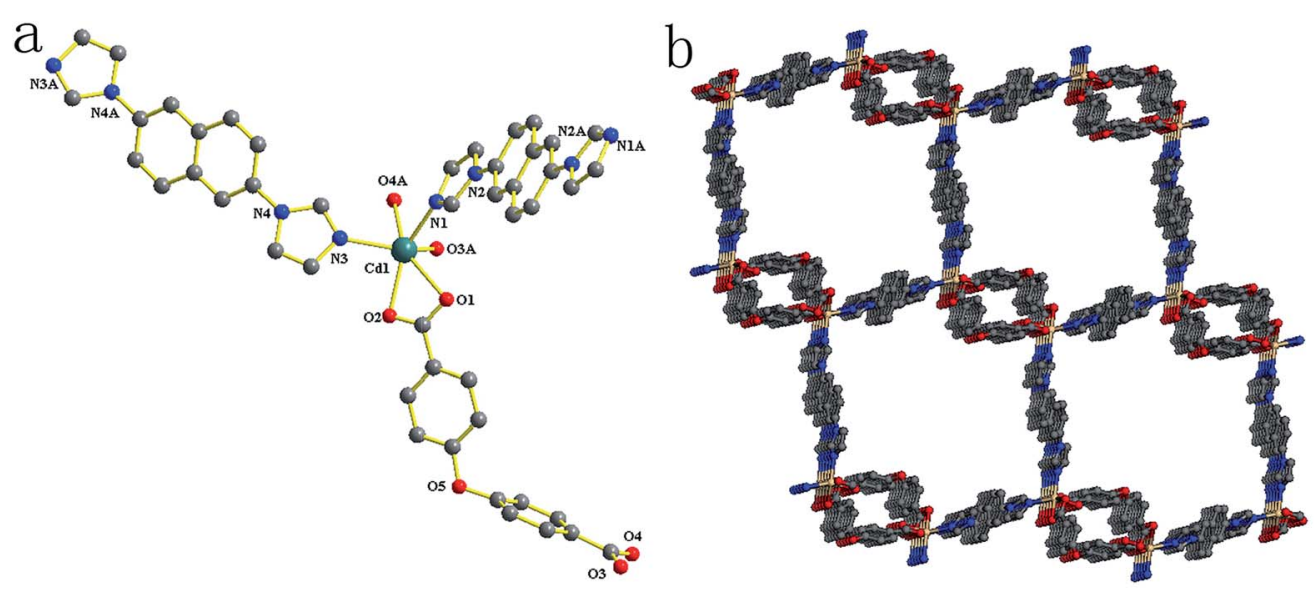

c
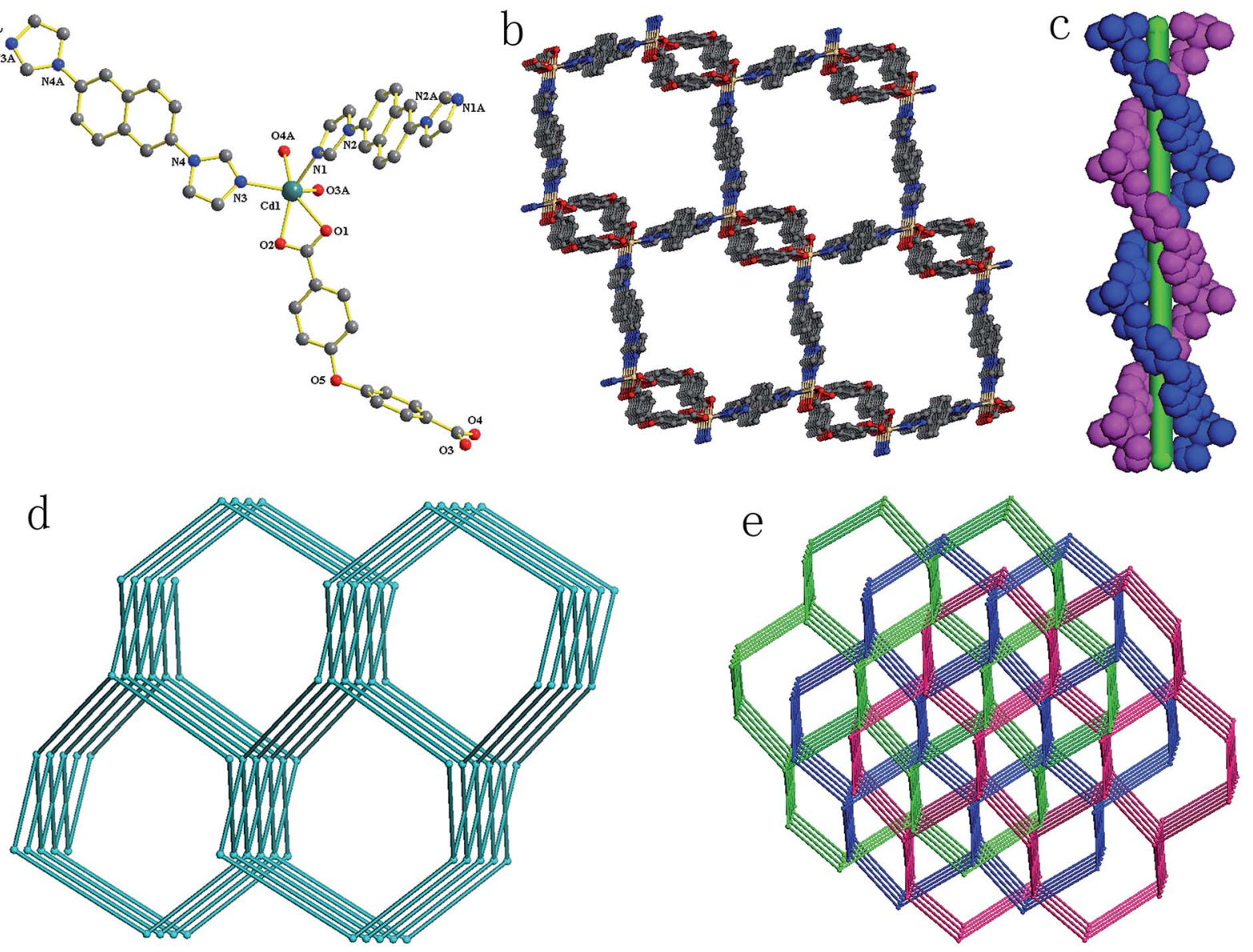

Fig. 1 (a) Coordination environment of $\mathrm{Cd}^{2+}$ ion in complex 1. The hydrogen atoms are omitted for clarity. (b) The perspective of the framework. (c) The perspective view of the double helix constructed from 2,6-bin and $\mathrm{Cd}^{2+}$ ions. (d) The schematic view of the 4T25 underlying net. (e) The schematic view of the three-fold interpenetration of 4 T25 net. 
bond angles are within the normal range (Table S1 in the ESI $\dagger$ ). The odc ${ }^{2-}$ anion connects two Cd(II) atoms through two chelate carboxlylates. The 2,6-bin ligand acts as a linker to bridge two Cd(II) atoms. In compound 1 , every two odc ${ }^{2-}$ anions are connected by $\mathrm{Cd}$ (II) atoms to give a $1 \mathrm{D}$ helical chain with a pitch of 24.54 A, corresponding to the double length of $b$ axis. Two such chains interweave together to assemble a double helix (Fig. 1c). These helixes are bridged by the 2,6-bin to build a 3D framework (Fig. 1b). Based on the concept of topology, ${ }^{\mathbf{1 0}}$ the framework can be simplified into a 4-connected $4 \mathbf{T 2 5}$ network, with the point symbol of $\left(6^{5} \cdot 8\right)$ (Fig. 1d). The potential voids are filled via mutual interpenetration of two independent equivalent networks, giving a rise to a 3-fold interpenetrating network (Fig. 1e). The 4T25 features self-catenation, ${ }^{11}$ which is detected as catenation of strong 10-rings and 14-rings of the same net, when odc ${ }^{2-}$ ligand is presented by 2-coordinated node to avoid edge-crossings (Fig. $\mathrm{S} 7 \dagger$ ). The catenation in the net originates from interweaving of the helical chains [Cd(odc)]. The same topology was found before only in one compound, $[\mathrm{Zn}(\mathrm{tpdc})(\mathrm{bpmp})]\left(\mathrm{H}_{2} \mathrm{tpdc}=\right.$ $1,1^{\prime}: 3^{\prime}, 1^{\prime \prime}$-terphenyl-4,4"-dicarboxylic acid; bpmp $=1$,4-bis(3-pyridylmethyl)piperazine). ${ }^{12}$

\section{Structure description of 2}

Compound 2 crystallizes in a monoclinic space group $P 2_{1} / c$. In the asymmetric unit, there exists one crystallographically unique $\mathrm{Cd}(\mathrm{II})$ atom, one $\mathrm{tdc}^{2-}$ anion, two half 2,6-bin ligands and one coordinated water molecule. As shown in Fig. 2a, the $\mathrm{Cd}(\mathrm{II})$ atom is surrounded by four oxygen atoms from two $\mathrm{tdc}^{2-}$ anions and one water molecule (Cd-O, 2.256(3)-2.333(2) $\AA$ ), and two nitrogen atoms from two 2,6-bin ligands (Cd-N, 2.274(3)-

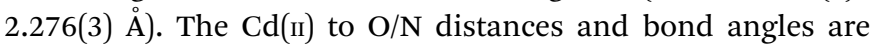
within the normal range (Table $\mathrm{S} 2$ in the ESI $\dagger$ ). The $\operatorname{tdc}^{2-}$ anion connects two Cd(II) atoms through one monodentate and one chelate carboxlylate. The 2,6-bin ligand acts as a linker to bridge two Cd(II) atoms. Thus, the Cd(II) atoms are joined by the organic ligands into framework of dia topology (Fig. 2b). Within the framework, the neighboring $\mathrm{Cd}(\mathrm{II})$ atoms are separated by distances of $15.67 \AA, 16.23 \AA$ (through 2,6-bin) and $10.91 \AA$ (via $\left.\mathrm{tdc}^{2-}\right)$. A single adamantanoid cage is illustrated in Fig. 2c, which exhibits maximum dimensions of $40.33 \AA \times 34.04 \AA \times$ $32.01 \AA \times 29.30 \AA$ (corresponding to the longest intracage Cd $\cdots$ Cd distances). Because of the spacious nature of the single a

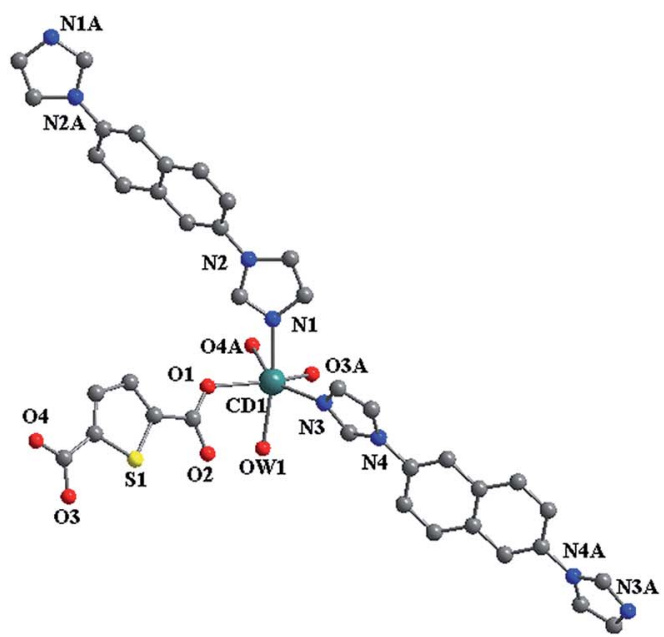

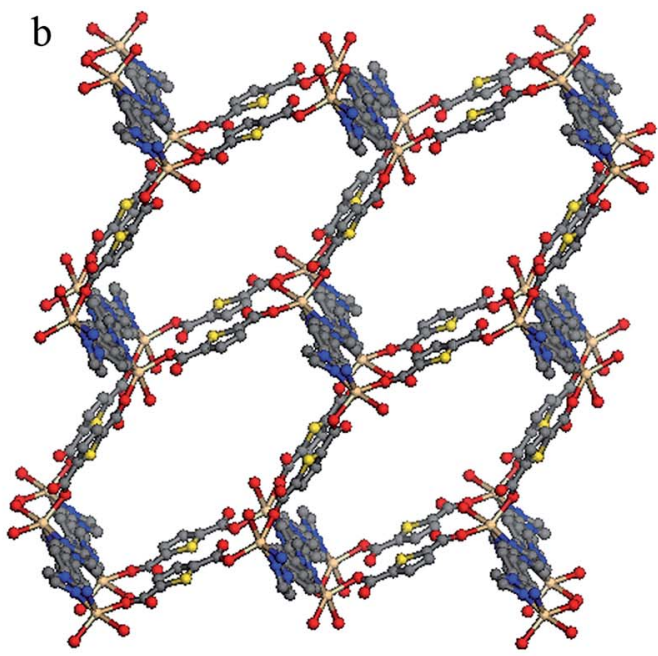

d
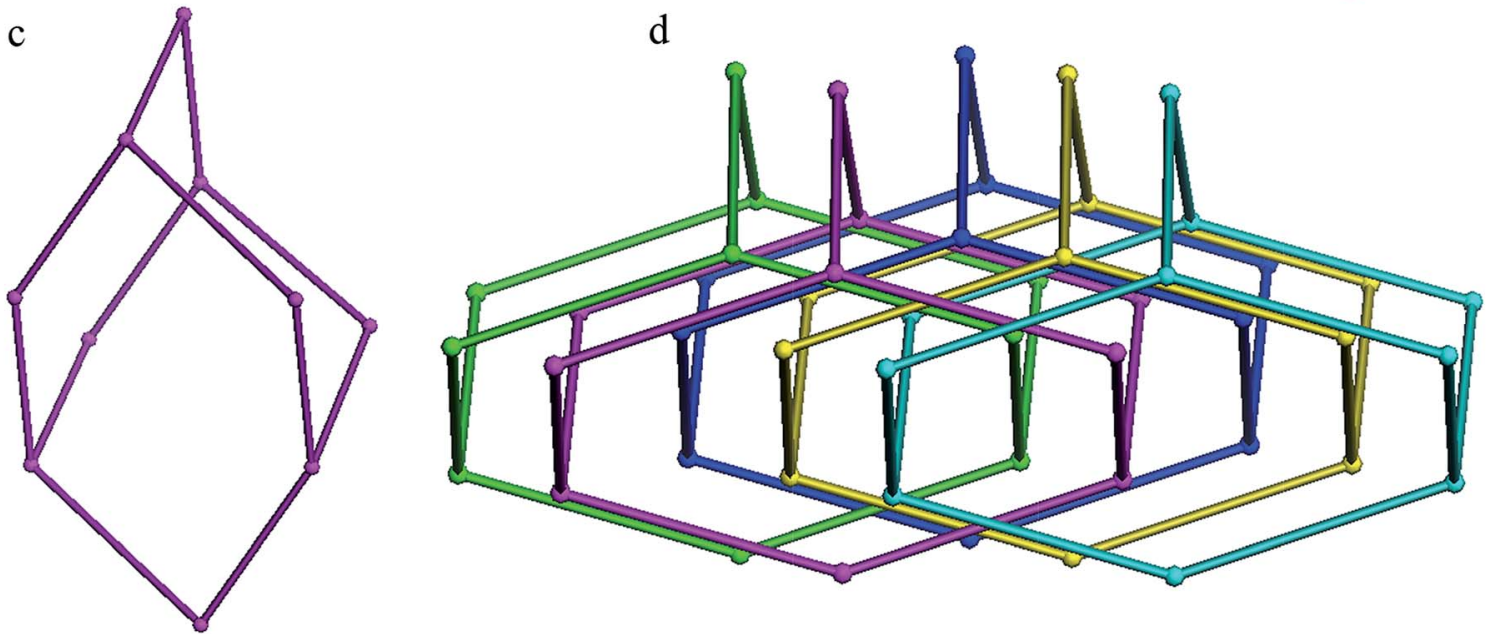

Fig. 2 (a) Coordination environment of $\mathrm{Cd}^{2+}$ ion in complex 2. The hydrogen atoms are omitted for clarity. (b) The perspective of the dia framework. (c) The schematic view of the single adamantanoid cage. (d) The schematic view of four-fold interpenetration of dia net. 
network, the potential voids are filled via mutual interpenetration of the other four independent equivalent frameworks, generating a five-fold interpenetrating architecture (Fig. 2d).

\section{Structure description of 3}

Compound 3 crystallizes in a monoclinic space group $P 2_{1} / c$. In the asymmetric unit, there exists one crystallographically unique $\mathrm{Cd}$ (II) atom, one bzdc ${ }^{2-}$ anion, two half 2,6-bin ligands and two uncoordinated DMF molecules. As shown in Fig. 3a, the $\mathrm{Cd}(\mathrm{II})$ atom is coordinated by four oxygen atoms from two bzdc $^{2-}$ anions (Cd-O, 2.2787(18)-2.4132(18) ^) and two nitrogen atoms from two 2,6-bin ligands (Cd-N, 2.238(2)-
2.256(2) $\AA$ ). The $\mathrm{Cd}(\mathrm{II})$ to $\mathrm{O} / \mathrm{N}$ distances and bond angles are within the normal range (Table S3 in the ESI†). The bzdc ${ }^{2-}$ anion connects two Cd(II) atoms through two chelate carboxylates. The 2,6-bin ligands act as linkers to join two Cd(II) atoms. In compound 3 , the $\mathrm{Cd}(\mathrm{II})$ atoms are bridged by organic ligands to assemble a 2D undulated framework of sql topology (Fig. 3b). The neighboring $\mathrm{Cd}(\mathrm{II})$ atoms are separated by distances of 15.59 $\mathrm{A}, 16.28 \AA$ (through 2,6-bin) and $14.86 \AA$ (via bzdc ${ }^{2-}$ ). The void space in the single framework is so large that three identical frameworks having one middle plane catenate each other to form a $2 \mathrm{D} \rightarrow 2 \mathrm{D}$ polycatenane of frequently observed pattern, which can be described by $\mathbf{8 L 2 3}$ extended ring net (Fig. 3d). ${ }^{\mathbf{1 3}}$ For the mean planes of these three layers are parallel and

a
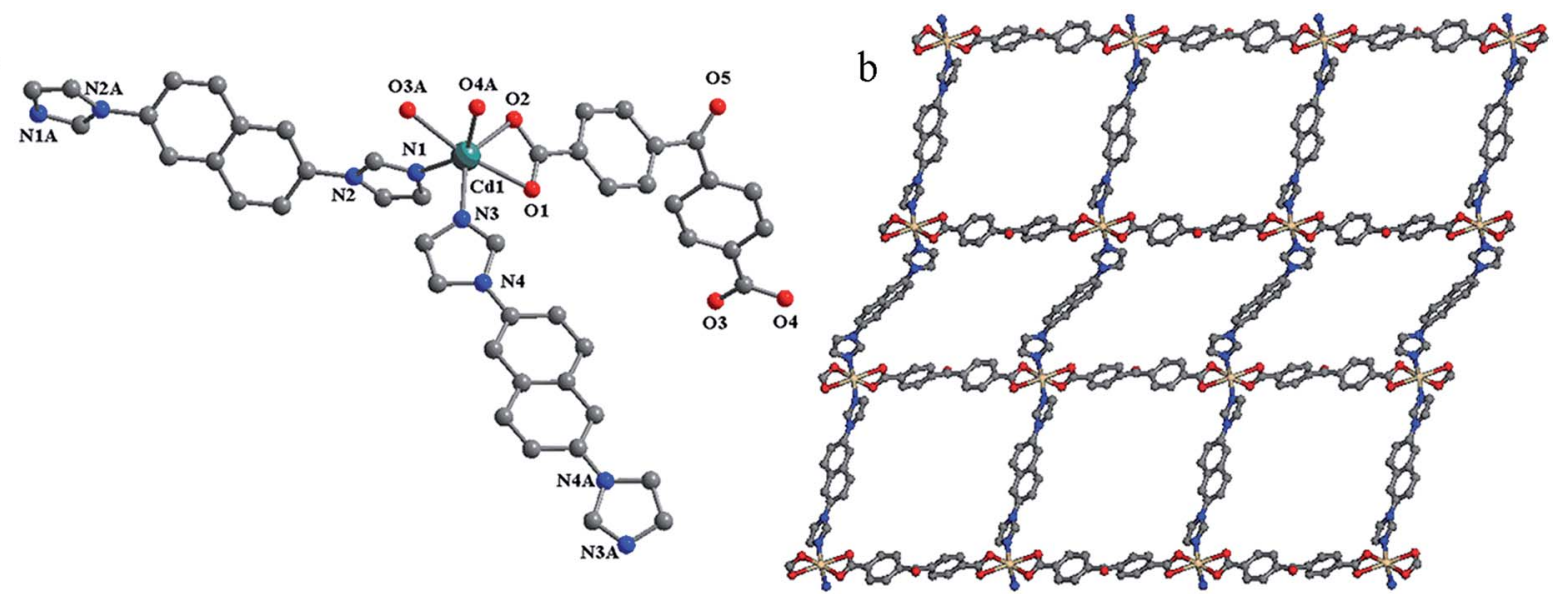

C

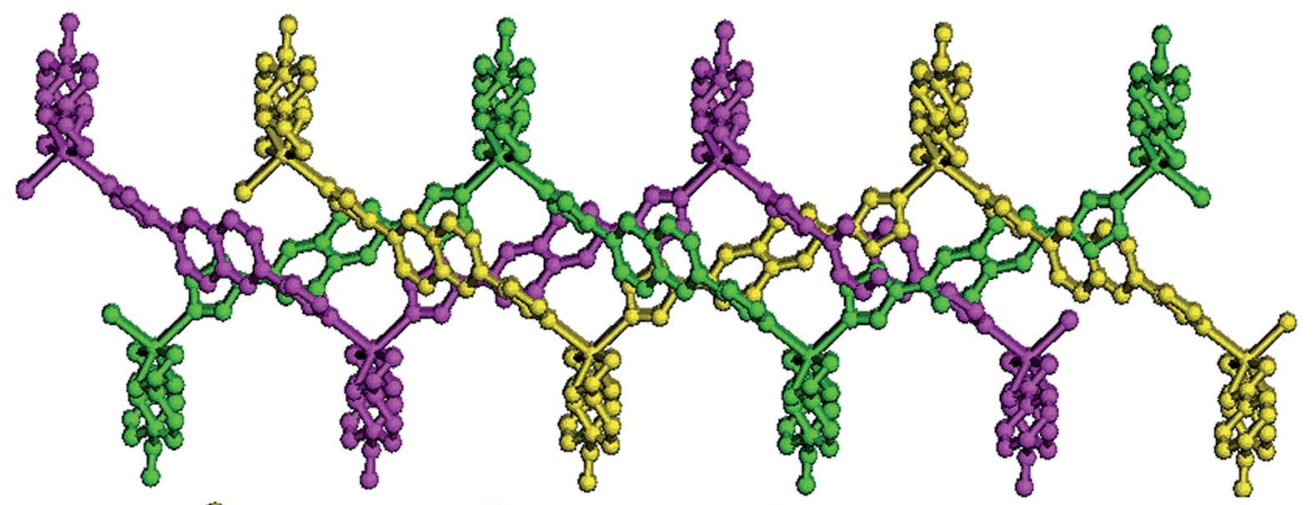

d

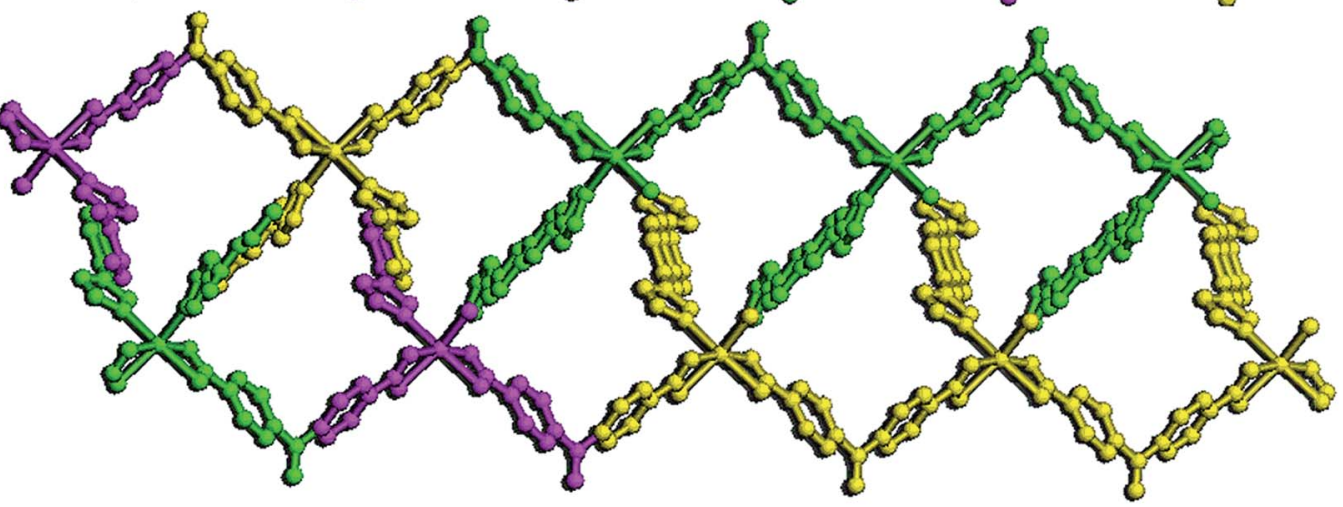

Fig. 3 (a) Coordination environment of $\mathrm{Cd}^{2+}$ ion in complex 3 . The hydrogen atoms and lattice DMF molecules are omitted for clarity. (b) The perspective view of 2D sql layer. (c) The perspective view of $2 \mathrm{D} \rightarrow 2 \mathrm{D}$ polycatenane of three-fold interpenetration of sql framework. (d) The perspective view of the $1 \mathrm{D}$ channels in complex 3. 
coincident, we can see that along the $a$ axis there still exist 1D open channels, which are occupied by the uncoordinated DMF molecules (Fig. 3e). The void space accounts for approximately $32.7 \%$ of the whole crystal volume as obtained by PLATON analysis.

\section{Structure description of 4}

Compound 4 crystallizes in a triclinic space group $P \overline{1}$. In the asymmetric unit, there exists one crystallographically unique $\mathrm{Cd}(\mathrm{II})$ atom, one $\mathrm{hfdc}^{2-}$ anion and two half 2,6-bin ligands. As shown in Fig. 4a, the Cd(II) atom is coordinated by three oxygen atoms from two $\mathrm{hfdc}^{2-}$ anions (Cd-O, 2.2175(17)-2.403(3) $\mathrm{\AA}$ ) and two nitrogen atoms from two 2,6-bin ligands (Cd-N, 2.235(2)-2.245(2) $⿱$ ). The $\mathrm{Cd}(\mathrm{II})$ to $\mathrm{O} / \mathrm{N}$ distances and bond angles are within the normal range (Table $\mathrm{S} 4$ in the ESI $\dagger$ ). The hfdc $^{2-}$ anion connects two Cd(II) atoms by one monodentate and one chelate carboxylates. The 2,6-bin ligands act as linkers to bridge two $\mathrm{Cd}$ (II) atoms. In compound 4 , the $\mathrm{Cd}(\mathrm{II})$ atoms are joined by organic ligands to assemble a framework of sql topology (Fig. 4b). Within the framework, the neighboring Cd(II) atoms are separated by distances of $15.53 \AA$, $15.57 \AA$ (through 2,6-bin) and $14.68 \AA$ (by hfdc ${ }^{2-}$ ). In order to minimize the space vacuum and stabilize the framework, each undulated layer catenates with two others from above and below. Although the catenated nets in $\mathbf{4}$ also have parallel mean planes, different from 3 , these mean planes are not coincident and the neighbors are separated by distances of $4.53 \AA$, thus giving a $2 \mathrm{D} \rightarrow 3 \mathrm{D}$ polycatenane. This polycatenated system can be described by extended ring net with topology hex frequent for 2D coordination polymers (Fig. $4 \mathrm{c}$ and d). ${ }^{13}$

\section{Structure description of 5}

Compound $\mathbf{5}$ crystallizes in a triclinic space group $P \overline{1}$. The asymmetric unit contains one and a half Cd(II) atoms, one tpo ${ }^{3-}$ anion, one and a half 2,6-bin, two coordination water molecules, one lattice water molecule and one lattice DMF molecule. As shown in Fig. 5a, there are two crystallographically Cd(II) atoms in compound 5 . Both $\mathrm{Cd} 1$ and $\mathrm{Cd} 2$ are six-coordinated in distorted octahedral coordination geometries, but their coordination environments are entirely different. Cd1 is coordinated by two nitrogen atoms from two 2,6-bin ligands (Cd-N, 2.262(3)-2.299(3) $\mathrm{A}$ ), and four oxygen atoms from three tpo ${ }^{3-}$ anions and one water molecule (Cd-O, 2.272(3)-2.448(3) ^). Cd2 is coordinated by two nitrogen atoms from one 2,6-bin ligands (Cd-N, 2.271(3) Å), and four oxygen atoms from two tpo ${ }^{3-}$ anions and two water molecules (Cd-O, 2.285(3)-2.318(3) А̊). The $\mathrm{Cd}(\mathrm{II})$ to $\mathrm{O} / \mathrm{N}$ distances and bond angles are within the normal range (Table S5 in the ESI $\dagger$ ). The tpo ${ }^{3-}$ anion links four Cd(II) atoms by two monodentate and one monodentatebridging carboxylates. Cd1 and its symmetry-related Cd1A are bridged by two $\mu_{2}-\mathrm{O} 3$ atoms from the monodentate-bridging carboxylates into a binuclear $\mathrm{Cd}_{2}$ unit, with a $\mathrm{Cd} 1 \cdots \mathrm{Cd} 1 \mathrm{~A}$ distance of $3.65 \AA$ and a Cd1-O3-Cd1A angle of $99.68^{\circ}$. Each binuclear unit is surrounded by eight organic ligands (four 2,6bin and four tpo ${ }^{3-}$ ), each $\mathrm{Cd} 2$ atom coordinates four organic ligands (two 2,6-bin and two tpo ${ }^{3-}$ ), and each tpo ${ }^{3-}$ anion connects one $\mathrm{Cd} 2$ atom and two binuclear units. Topologically, the tpo ${ }^{3-}$ anions can be considered as 3-connected nodes, Cd2 atoms can be viewed as 4-connected nodes, and the binuclear units can be reduced to 6-connected nodes (Fig. 5b). Therefore, the whole $3 \mathrm{D}$ framework can be simplified as a $(3,4,6)$ -
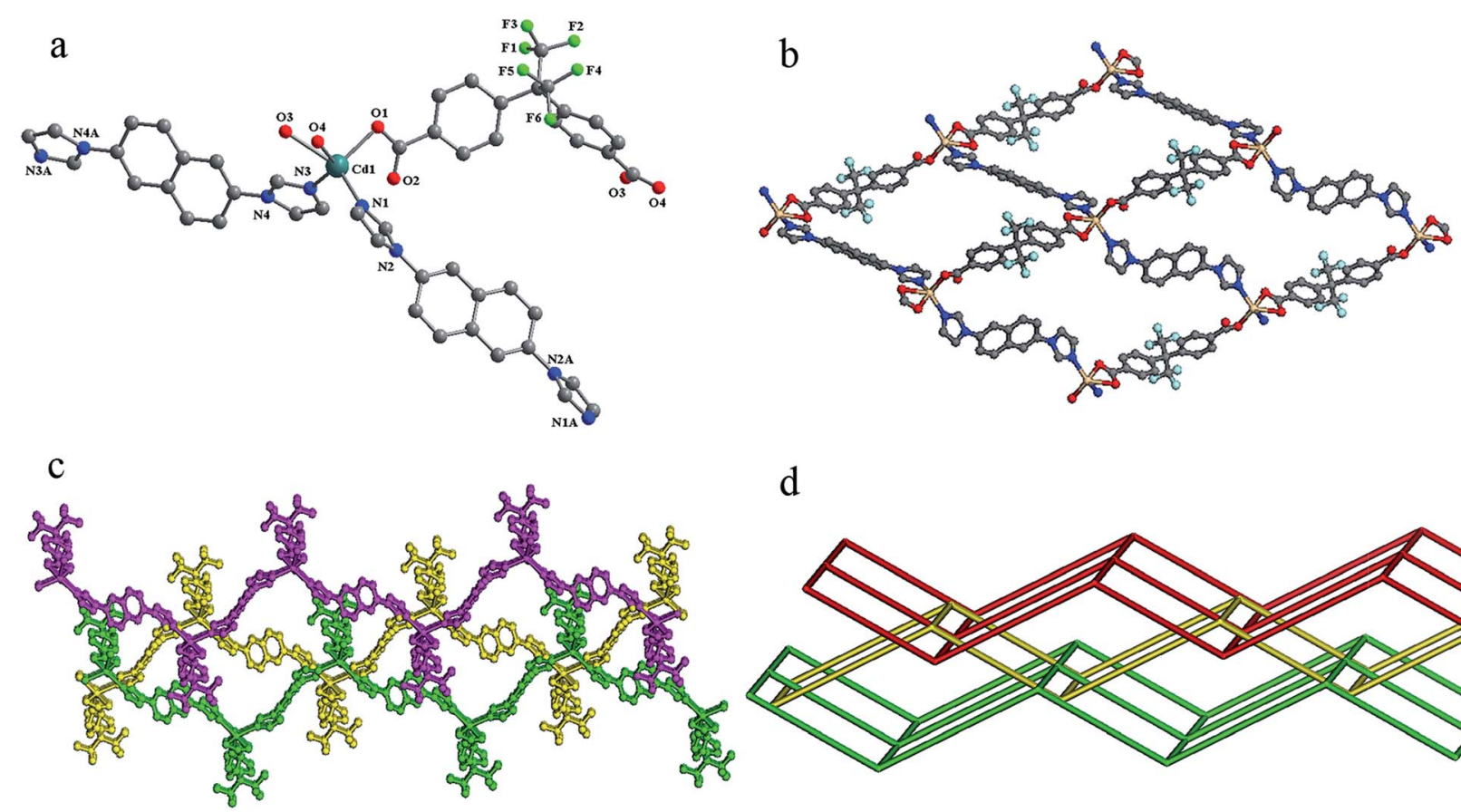

d

Fig. 4 (a) Coordination environment of $\mathrm{Cd}^{2+}$ ion in complex 4 . The hydrogen atoms are omitted for clarity. (b) The perspective view of $2 \mathrm{D}$ sql layer. ( $c$ and d) The perspective and schematic views of 2D $\rightarrow$ 3D parallel polycatenated of sql nets. 

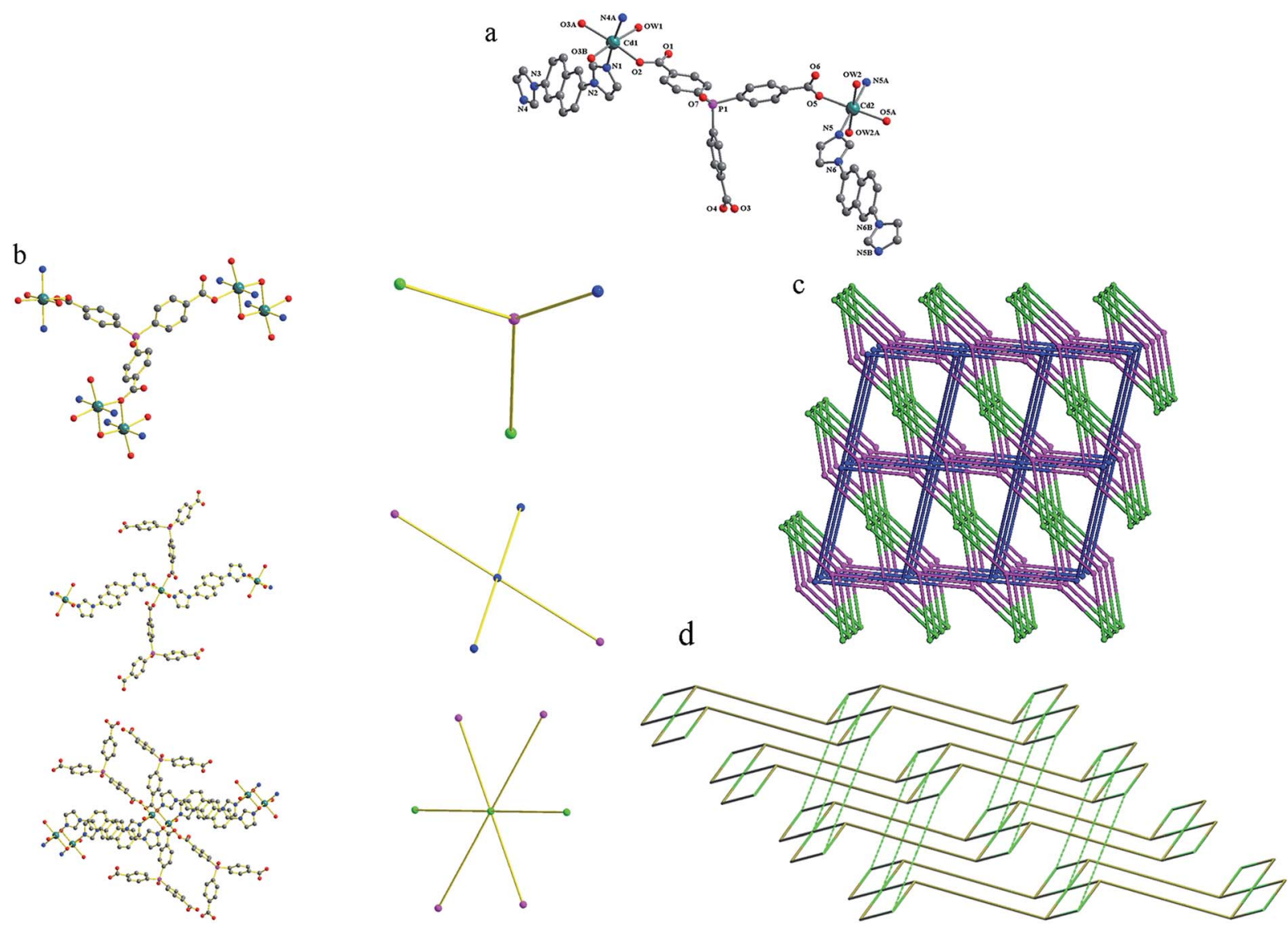

Fig. 5 (a) Coordination environment of $\mathrm{Cd}^{2+}$ ion in complex 5 . The hydrogen atoms and lattice DMF molecules are omitted for clarity. (b) The perspective and schematic views of the 3-, 4- and 6-connected nodes. (c) The schematic view of the $(3,4,6)$-connected net of 3,4,6T206 topology. (d) Representation of 3,4,6T206 net as a system of parallel 3,4-c bex subnets (thick edges). The dashed green edges are corresponded to 2,6-bin ligands.

connected net of 3,4,6T206 topology (Fig. 5c). To the best of our knowledge, there is only one coordination polymer of this topology: $\left\{\left[\mathrm{Co}_{3}(\mathrm{~L})(\mathrm{BPY})_{1.5}\right] \cdot \mathrm{H}_{2} \mathrm{O}\right\}_{n}$ (CSD RefCode EWUHUB: $\mathrm{H}_{3} \mathrm{~L}$ $=4$-methyoxy-3,5-bis(4-carboxyphenyl)benzoic acid, $\mathrm{BPY}=4,4^{\prime}$ bipyridine). ${ }^{6 c}$ The 3,4,6T206 net has a peculiar property of selfcatenation. This property originates from mixing ligands of different types into one framework. The tricarboxilate tpo ${ }^{3-}$ ligand forms $2 \mathrm{D}$ subnet (partial composition $\left[\mathrm{Cd}_{3}(\mathrm{tpo})_{2}\right]$ ) of 3,4c bex topology, which is very common for $2 \mathrm{D}$ coordination polymers. ${ }^{14}$ The $2 \mathrm{D}$ subnets pack parallel to each other, and 2,6bin ligands steach them into $3 \mathrm{D}$ framework passing through strong 6-rings of the bex layers (Fig. 5d).

\section{Structure description of 6}

Compound 6 crystallizes in a triclinic space group $C 2 / c$. The asymmetric unit contains one and a half Zn(II) atoms, one btb ${ }^{3-}$ anion and half a 2,6-bin ligand. As shown in Fig. 6a, there are two crystallographically different Zn(II) atoms in compound 6. $\mathrm{Zn} 1$ coordinates six oxygen atoms from six $\mathrm{btb}^{3-}$ anions to give a distorted octahedral geometry (Zn-O, 2.067(2)-2.1019(19) ̊). $\mathrm{Zn} 2$ is ligated by one nitrogen atom from one 2,6-bin ligand $(\mathrm{Zn}-\mathrm{N}, 2.005(2) \AA)$ and four oxygen atoms from four $\mathrm{btb}^{3-}$ anions (Zn-O, 1.908(2)-1.962(2) ̊) into a distorted square pyramid geometry. The Zn(II) to O/N distances and bond angles are within the normal range (Table S6 in the ESI + ). The btb ${ }^{3-}$ anion links six Zn(II) atoms by three chelate carboxylates. The $\mathrm{Zn} 1$ atom is situated at an inversion center and it is connected with two neighboring $\mathrm{Zn} 2$ atoms by six bis(monodentate) carboxylates to form a trinuclear $\left[\mathrm{Zn}_{3}\left(\mathrm{CO}_{2}\right)_{6}\right]$ cluster. Without considering the linear 2,6-bin ligands, these clusters are combined by the btb ${ }^{3-}$ anions into a $(3,6)$-connected net of flu$3,6-C 2 / c$ topology. When the linear ligands are taken into account, topologically, the $\mathrm{btb}^{3-}$ anions can be considered as 3connected nodes (Fig. $6 \mathrm{c}$ ), and the trinuclear $\left[\mathrm{Zn}_{3}\left(\mathrm{CO}_{2}\right)_{6}\right]$ cluster can be viewed as 8-connected nodes (Fig. 6d). Thus, the whole 3D framework can be simplified as a $(3,8)$-connected net of 3,8T72 topology (Fig. 6b and e). On the bases of automatic analysis by ToposPro, this is the second example of such topology, the first one was $\left[\mathrm{Co}_{3}(\mathrm{~L})_{2} \text { (DPDP) }\right]_{n}$ (CSD RefCode GUFQIJ: $\mathrm{H}_{3} \mathrm{~L}=4,4^{\prime}, 4^{\prime \prime}$-(nitrilotris-(methylene))tribenzoic acid, DPDP $=4,4^{\prime}$-(2,5-dibutoxy-1,4-phenylene)-dipyridine). ${ }^{15}$ The 3,8T72 net is also can be considered as self-catenated, where strong 4-rings (which are also strong rings of subnet flu-3,6-C2/ c) are threaded by edges corresponded to 2,6-bin ligand (Fig. 6f).

Thermal analysis. To characterize the thermal stabilities of compounds 1-6, their thermal behaviors were investigated by TGA (Fig. S8 in the ESI $\dagger$ ). The experiments were performed on 


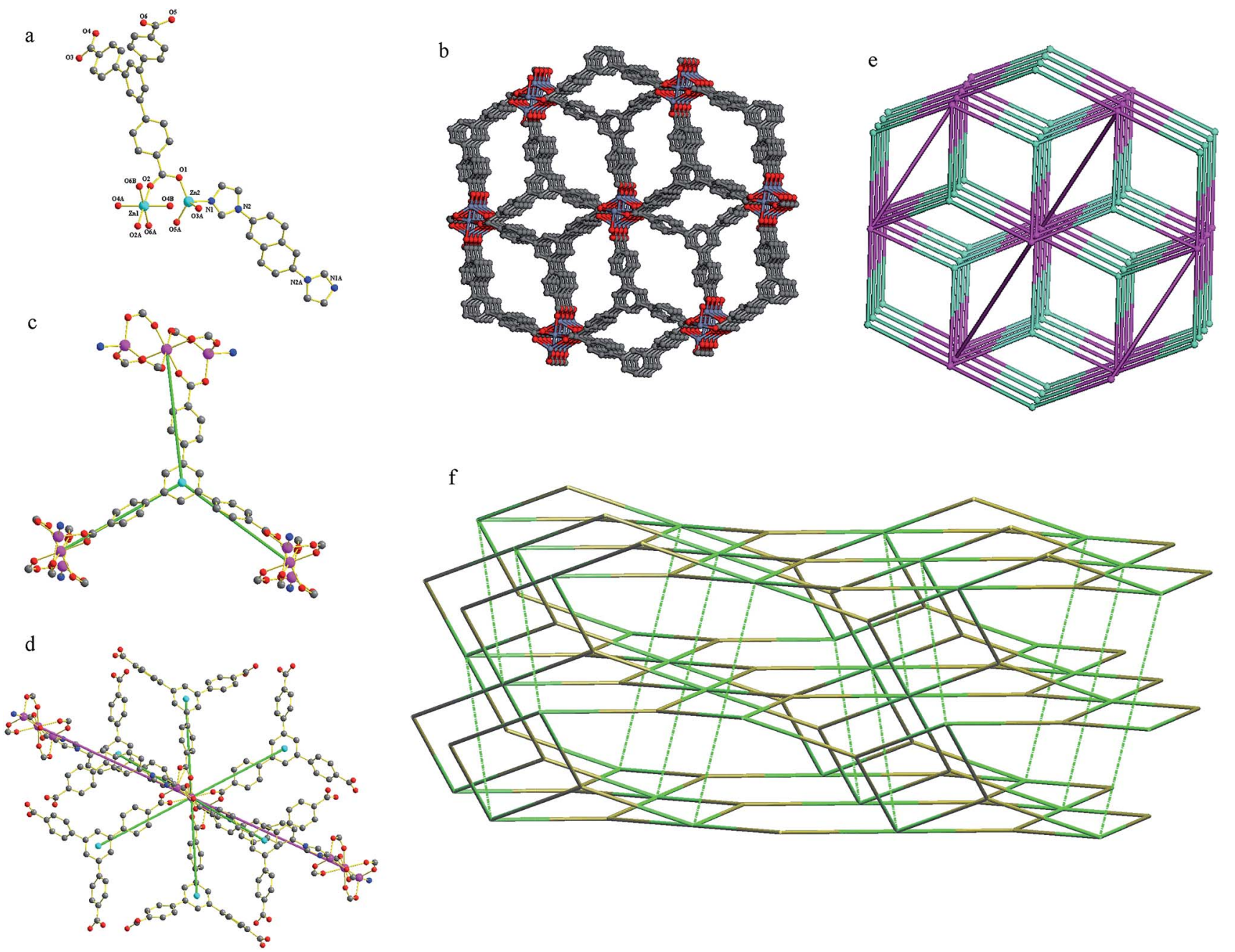

Fig. 6 (a) Coordination environment of $\mathrm{Zn}^{2+}$ ion in complex 6 . The hydrogen atoms are omitted for clarity. (b) The schematic view of (3,6)connected flu-3,6-C2/c net combined by $\mathrm{Zn}^{2+}$ ion and btb ${ }^{3-}$ anions. (c and d) The perspective views of the 3- and 8-connected nodes. (e) The schematic view of the (3,8)-connected net of 3,8T72 topology. (f) Representation of $3,8 T 72$ net as the flu-3,6-C2/c subnet (thick edges) without removed (dashed lines) edges corresponded to 2,6-bin ligands.

samples consisting of numerous single crystals powder of 1-6 under nitrogen atmosphere with a heating rate of $10^{\circ} \mathrm{C} \mathrm{min}^{-1}$. For 1, the weight loss in the range of $25-270{ }^{\circ} \mathrm{C}$ is ascribed to release of dimethylamine molecules (obsd $3.56 \%$, calcd $3.46 \%$ ). The decomposition of the framework occurs at ca. $380{ }^{\circ} \mathrm{C}$. Compound 2 is stable up to $c a .240^{\circ} \mathrm{C}$. For 3 , the weight loss in the range of $130-320{ }^{\circ} \mathrm{C}$ is attributed to release of DMF molecules (obsd 16.9\%, calcd 18.6\%). The decomposition of the framework occurs at $c a .350{ }^{\circ} \mathrm{C}$. Compound 4 is stable up to $c a$. $360{ }^{\circ} \mathrm{C}$. For 5 , the weight loss in the range of $25-230{ }^{\circ} \mathrm{C}$ is attributed to release of DMF and water molecules (obsd $11.3 \%$, calcd $11.6 \%$ ). The framework is stable up to $c a .300^{\circ} \mathrm{C}$. For 6 , the weight loss in the range of $25-240{ }^{\circ} \mathrm{C}$ is attributed to the release of DMF molecules (obsd 30.5\%, calcd 30.6\%). The framework is stable up to $c a .340{ }^{\circ} \mathrm{C}$.

\section{Adsorption capability towards methyl orange}

The capture abilities of 1-6 towards to methyl orange (MO) were evaluated. The adsorption experiments were run as follows:
$5 \mathrm{mg}$ of host material was immersed to $10 \mathrm{~mL}$ of $\mathrm{MO}$ aqueous solutions $\left(4 \times 10^{-5} \mathrm{~mol} \mathrm{~L}^{-1}\right)$, respectively. The clear solution after centrifuging was measured by UV/vis spectra to monitor the MO concentration at different time intervals. As shown in Fig. 7, for compounds 1-5, within 10-30 minutes, the adsorption efficiencies of MO reached $99.3 \%$ for $1,97.9 \%$ for $3,93.0 \%$ for 4 and almost $100 \%$ for 2 and $\mathbf{5}$. Obviously, these compounds exhibit highly efficient adsorption to MO. Comparatively, compound 6 presents interesting adsorption behavior to MO: at 20 minutes, the adsorption of MO reached a maximum of $60.3 \%$; while, at 30 minutes, the value of adsorption decreased to $16.3 \%$, which means the desorption of MO from compound 6; till to 60 minutes, the value of adsorption was stable at $55.4 \%$.

From the structures above, we can find that only compounds 3 and 6 exhibit open frameworks, but the channels with minor window size are hard to trap MO molecules. Thus, the adsorption of 1-6 occurs mainly due to the surface interactions. In compound 6, the $\mathrm{Zn}_{3}$ cluster is surrounded by six bis(monodentate) carboxylates and the axial position of metal clusters are 

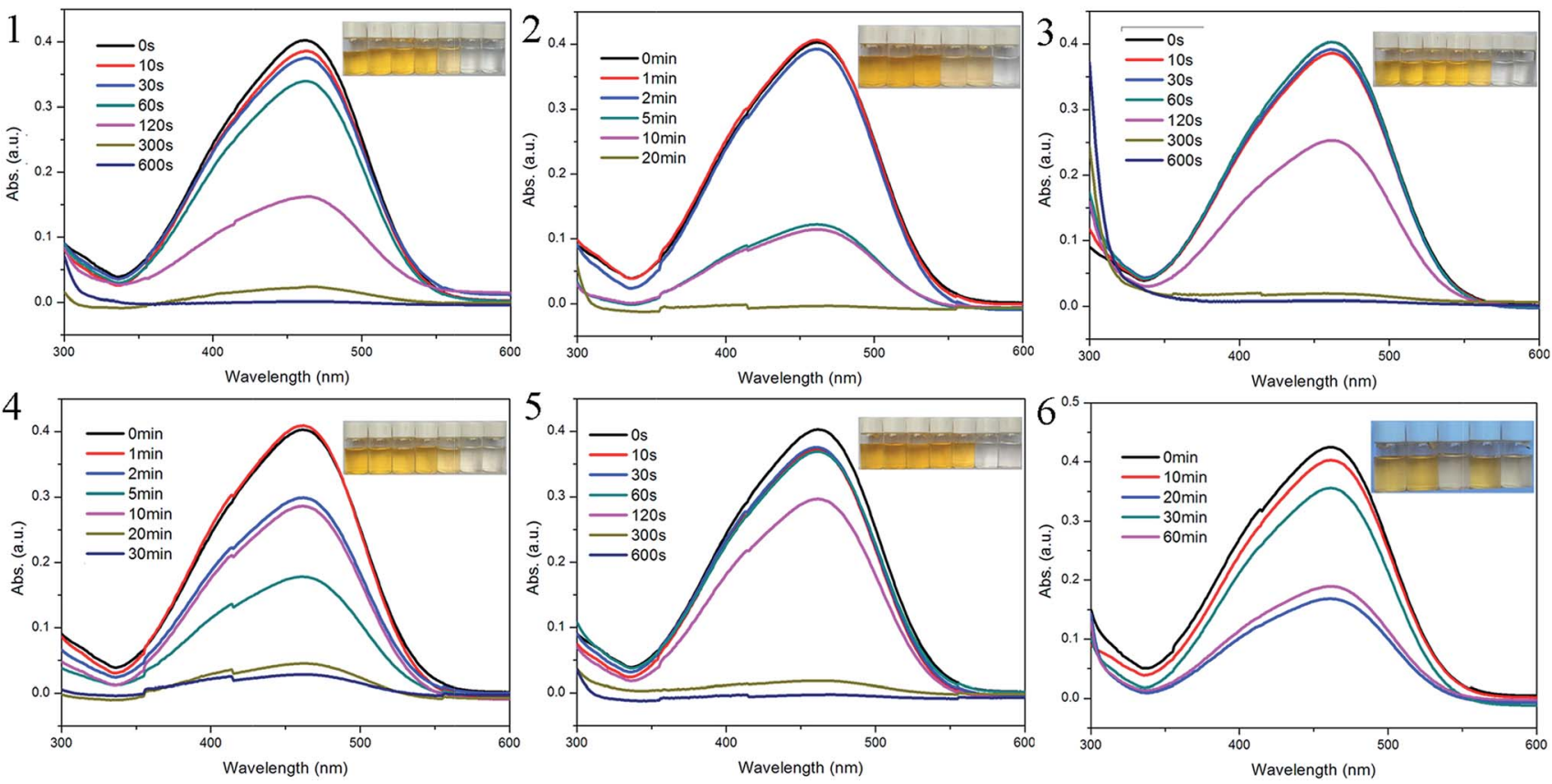

Fig. 7 UV-vis spectra of MO with sample 1-6 at given intervals, respectively. Inset: photographic images of MO solutions for different period of time.

occupied by 2,6-bin ligands, which blockages the accessment of MO molecules. Thus, the adsorption is mainly ascribed by the $\pi-\pi$ conjugations between benzene rings from host framework and MO molecules. ${ }^{16}$ Such weak interactions induce the spontaneous desorption of MO molecules in the process of adsorption. While, in compounds $\mathbf{1 - 5}$, besides the $\pi-\pi$ conjugation effects, the bigger ionic radius of $\mathrm{Cd}(\mathrm{II})$ is favorable to the electrostatic interaction between central metal ions and anionic MO molecules. ${ }^{17}$ Such synergistic effect definitely improves the adsorption ability of host materials.

In order to confirm the mechanism of MO adsorption for 1-6, the adsorption-desorption cycle tests were evaluated. The release tests were carried out with methanol as the elution solvent. The MO-uptaked 1-6 were dispersed in $10 \mathrm{ml}$ methanol by sonication for $5 \mathrm{~min}$ and centrifuged. After 5 times, the combined solution was measured by UV/vis spectra to monitor the MO concentration. The results revealed that the adsorbed MO molecules can be released almost completely (Fig. S9-S14, ESI $\dagger$ ). Obviously, the weak surface interactions due to the $\pi-\pi$ conjugation effects favor the release of MO molecules from host frameworks in methanol. The PXRD patterns of MO-released 16 indicate the stability of crystalline sample (Fig. S1-S6 in ESI†े). Meanwhile, the MO-released 1-6 still show good reusability of MO adsorption (Fig. S9-S14, ESI $†$ ). The adsorption capacities of 1-6 towards cationic dyes methylene blue (MB) and rhodamine $\mathrm{B}(\mathrm{RhB})$ were also evaluated. As shown in Fig. S15-S20 (ESI), $\dagger$ the UV/vis adsorption spectra showed that these compounds almost do not exhibit adsorption of $\mathrm{MB}$ and $\mathrm{RhB}$, in spite of their larger rigid aromatic cycle comparing to $\mathrm{MO}$ molecule. The results further demonstrated that the electrophilicity of central metal ions plays an important role for the adsorption of anionic dye.

\section{Conclusions}

In this study, based on the mixed-ligand strategy, six new MOFs have been synthesized an structurally characterized. Compound 1 exhibits a three-fold interpenetration of 4T25 network. Compound 2 presents a five-fold interpenetration of dia network. Compound 3 displays a $2 \mathrm{D} \rightarrow 2 \mathrm{D}$ three-fold interpenetration of sql layers. Compound 4 features a $2 \mathrm{D} \rightarrow 3 \mathrm{D}$ parallel polycatenation of sql layers. Compound 5 exhibits an unusual 3,4,6-connected self-catenated network of 3,4,6T206 topology. Compound 6 shows a rare 3,8-connected selfcatenated network of 3,8T72 topology. The result of this study demonstrates that the rational selection of organic ligands with specific rigidity and length is an effective approach to the construction of entangled motifs. Almost all of these compounds exhibit selective adsorption to anionic methyl orange, which demonstrates that the surface physicochemical interactions including electrostatic interactions and $\pi-\pi$ conjugation effects play a significant synergistic effect in the adsorbing dyes. These compounds not only fill the aesthetic diversity of coordinative network chemistry, but also may provide a potential way to the selective design of versatile network-based materials.

\section{Conflicts of interest}

There are no conflicts to declare.

\section{Acknowledgements}

The authors gratefully acknowledge the financial support for this work from the National Natural Science Foundation of 
China (No. 21601019), Jilin Natural Science Foundation of China (No. 20160414031GH) and Natural Science Foundation of Changchun Normal University (cscxy2017004, cxcxy2017028). EVA is gratefull to the Russian Science Foundation (Grant No. 16-13-10158).

\section{Notes and references}

1 (a) H. Xue, Q. H. Chen, F. L. Jiang, D. Q. Yuan, G. X. Lv, L. F. Liang, L. Y. Liu and M. C. Hong, Chem. Sci., 2016, 7, 5983; (b) V. Suba and G. Rathika, J. Adv. Phys., 2016, 5, 277; (c) A. V. Desai, B. Manna, A. Karmakar, A. Sahu and S. K. Ghosh, Angew. Chem., Int. Ed., 2016, 55, 7811; (d) S. X. Duan, J. X. Li, X. Liu, Y. N. Wang, S. Y. Zeng, D. D. Shao and T. Hayat, ACS Sustainable Chem. Eng., 2016, 4, 3368; (e) B. Wang, X. L. Lv, D. W. Feng, L. H. Xie, J. Zhang, M. Li, Y. B. Xie, J. R. Li and H. C. Zhou, J. Am. Chem. Soc., 2016, 138, 6204.

2 (a) V. K. Gupta and T. A. Saleh, Environ. Sci. Pollut. Res., 2013, 20, 2828; (b) A. Dey, S. K. Konavarapu, H. S. Sasmal and K. Biradha, Cryst. Growth Des., 2016, 16, 5976; (c) R. Bibi, L. F. Wei, Q. H. Shen, W. Tian, O. Oderinde, N. X. Li and J. C. Zhou, J. Chem. Eng. Data, 2017, 62, 1615; (d) M. L. Gao, W. J. Wang, L. Liu, Z. B. Han, N. Wei, X. M. Cao and D. Q. Yuan, Inorg. Chem., 2017, 56, 511.

3 (a) L. Zhou, C. Gao and W. J. Xu, ACS Appl. Mater. Interfaces, 2010, 2, 1483; (b) N. Peng, D. Y. Hu, J. Zeng, Y. Li, L. Liang and C. Y. Chang, ACS Sustainable Chem. Eng., 2016, 4, 7217; (c) V. K. Gupta and A. Nayak, Chem. Eng. J., 2012, 180, 81; (d) C. C. de Escobar, A. Fisch and J. H. Z. dos Santos, Ind. Eng. Chem. Res., 2015, 54, 254.

4 (a) J. B. DeCoste and G. W. Peterson, Chem. Rev., 2014, 114, 5695; (b) S. N. Zhao, X. Z. Song, M. Zhu, X. Meng, L. L. Wu, J. Feng, S. Y. Song and H. J. Zhang, Chem.-Eur. J., 2015, 21, 9748; (c) Y. B. He, W. Zhou, G. D. Qian and B. L. Chen, Chem. Soc. Rev., 2014, 43, 5657; (d) J. N. Hao and B. Yan, Adv. Funct. Mater., 2017, 27, 1603856.
5 (a) A. D. Pournara, S. Rapti, E. Skliri, G. S. Armatas, A. C. Tsipis and M. J. Manos, ChemPlusChem, 2017, 82, 1188; (b) M. M. Guo, S. Y. Liu, H. D. Guo, Y. Y. Sun, X. M. Guo and R. P. Deng, Dalton Trans., 2017, 46, 14988.

6 (a) Q. Chen, Q. Q. He, M. M. Lv, Y. L. Xu, H. B. Yang, X. T. Liu and F. Y. Wei, Appl. Surf. Sci., 2015, 327, 77; (b) W. Yan, L. J. Han, H. L. Jia, K. Shen, T. Wang and H. G. Zheng, Inorg. Chem., 2016, 55, 8816; (c) N. Zhao, F. X. Sun, N. Zhang and G. S. Zhu, Cryst. Growth Des., 2017, 17, 2453.

7 G. M. Sheldrick. SHELXS-97, Programs for X-ray Crystal Structure Solution, University of Göttingen, Göttingen, Germany, 1997.

8 G. M. Sheldrick. SHELXL-97, Programs for X-ray Crystal Structure Refinement, University of Göttingen, Göttingen, Germany, 1997.

9 A. Spek, Acta Crystallogr., Sect. D: Biol. Crystallogr., 2009, 65, 148.

10 (a) E. V. Alexandrov, V. A. Blatov, A. V. Kochetkov and D. M. Proserpio, CrystEngComm, 2011, 13, 3947; (b) V. A. Blatov, A. P. Shevchenko and D. M. Proserpio, Cryst. Growth Des., 2014, 14, 3576.

11 L. Carlucci, G. Ciani and D. M. Proserpio, Coord. Chem. Rev., 2003, 246, 247.

12 B. Liu, J. Coord. Chem., 2015, 68, 1251.

13 E. V. Alexandrov, V. A. Blatov and D. M. Proserpio, CrystEngComm, 2017, 19, 1993.

14 T. G. Mitina and V. A. Blatov, Cryst. Growth Des., 2013, 13, 1655.

15 C. L. Zhang, Y. L. Li, T. Wang, Z. M. Ju, H. G. Zheng and J. Ma, Chem. Commun., 2015, 51, 8338.

16 R. Bibi, L. F. Wei, Q. H. Shen, W. Tian, O. Oderinde, N. X. Li and J. C. Zhou, J. Chem. Eng. Data, 2017, 62, 1615.

17 (a) M. S. Bootharaju and T. Pradeep, Langmuir, 2013, 29, 8125; (b) M. Dan-Hardi, C. Serre, T. Frot, L. Rozes, G. Maurin, C. Sanchez and G. Ferey, J. Am. Chem. Soc., 2009, 131, 10857. 